\title{
The World Association for Emergency and Disaster Medicine: Origins, Present Status, and Future Directions
}

\author{
Steven J. Rottman, MD*
}

Resuscitology is something of a "new concept" in the history of medical sciences. It was just 30 years ago that Professors Elam, Ruben, Safar, and Keuwenhoven consolidated their independently formulated thoughts in cardiopulmonary resuscitation (CPR). Their vision resulted in much of what we teach and practice today. The extension into the prehospital arena of these life-supporting techniques, along with portable defibrillators and the out-of-hospital administration of cardiac medications was unheard of until the late 1960s. We had men walking on the moon before we had advanced cardiac life support practiced in the streets here on earth. At a 1973 international symposium on the delivery of emergency medical services (EMS) in Mainz, Germany, a handful of prominent physicians discussed the disparity between the potentials of modern resuscitation and its unavailability for most everyday emergencies. In 1976, ten concerned resuscitologists from seven countries met in Geneva to explore further the possibilities of improving the delivery of resuscitative care in daily life and for acute medical care following disasters. On 2 October 1976, the Club of Mainz was founded with the major objectives of fostering optimal resuscitation and life-support methodologies, both in everyday and in mass disaster emergencies, by combining scientific, social, and related information and experiences together with international communication and collaboration. The first president was the late Rudolph Frey, Chairman of Anesthesiology at the Gutenberg University in Mainz.

Initially, the membership was set at 100 nominated and elected members, but this limit was lifted as the experience relevant to the goals of the Club became more widespread in the world medical community. In order to reflect the more global membership of the organization, its name was changed in 1985 to the World Association for Emergency and Disaster Medicine (WAEDM). Currently, there are more than 500 members from 30 countries in the WAEDM.

One of the major activities of the Association is the convention of biennial congresses, where members and interested participants present scientific reports on emergency and resuscitation research, as well as accounts of major disasters that have occurred, and the strengths and pitfalls of the emergency responses to them. Previous congresses have been held in: Mainz, Germany; Pitsburgh, Pennsylvania, U.S.A.; Rome, Italy; Brighton, United Kingdom; Rio de Janeiro, Brazil; and Hong Kong. The 1991 Congress will be in Montreal, Canada, and Stockholm, Sweden, has been selected as the site for 1993. As the interest in disaster medicine has increased, the number of delegates to these congresses has risen accordingly.

A second significant activity of WAEDM was the establishment of a journal. First entitled Disaster Medicine. The publication, now in its fifth volume, has been renamed Prehospital and Disaster Medicine, and its international editorial review board includes physicians, paramedical personnel, and nurses from 14 nations. The aim of the ed-

* Secretary General, World Association for Emergency and Disaster Medicine (WAEDM)

Director, Center for Prehospital Care, UCLA Medical Center, Los Angeles, California, USA

Delivered to the International Conference on Disaster Medicine, presented on the initiative of the Ministry of Public Health of the USSR, in Moscow 22-23 May 1990 
itorial board is to provide researchers, teachers and practitioners with a readable, usable, and relevant source of current thinking and research in this field, while both maintaining an open forum for debate, controversy, and statements of position of both WAEDM, and the journal's co-sponsoring organization, the National Association of Emergency Medical Services Physicians.

The third major activity of WAEDM lies within its Task Force structure, a relatively recent innovation for the Association and a direct outgrowth of the 5th World Congress, held in 1987 in Rio de Janeiro. At that Congress, Task Forces on Chemical and Hazardous Materials Accidents, and International Disaster Responses were added to the existing one for Aircraft Incidents and Aeromedicine. During the next two years, members of these Task Forces worked to identify problems in these areas, researching existing solutions, and studying responses to previous incidents. The Task Forces met throughout the 6th World Congress on Emergency and Disaster Medicine, held in Hong Kong last September [1989]. Concrete recommendations were generated from each of these Task Forces, presented to and ratified by the General Assembly of the Congress. To introduce you to some of the ideas put forth by this Task Force process, I will highlight some of the recommendations of the Aircraft Disaster Task Force, and then provide a more detailed account of the activities of the Task Force on International Disaster Responses, of which I am the Chairman.

The Task Force on Aircraft Incidents and Aeromedicine brought together a number of international experts in the fields of airport disaster planning and practical management, and aviation medicine. During the Task Force discussions, consensus was reached on five major points and the following recommendations were developed:

1) Helicopters should have a role in the immediate care of the severely injured;

2) Abrupt decompression in commercial aircraft dictates the need for bet- ter oxygen delivery systems for passengers and flight attendants;

3) A standardized recording form should be used throughout the industry to document the incidence and outcome of medical emergencies in flight;

4) All commercial airline companies should adopt requirements to supply emergency drugs and equipment for in flight medical care. (The U.S. carriers specifically were identified as needing to upgrade this component of service.); and

5) WAEDM endorses the need to ban all aerobatic displays over crowded areas at air shows.

These five points were endorsed by the Congress General Assembly, and members of the Task Force were to continue to pursue ways to fulfill the goals put forth at the Congress.

During the deliberations of the Task Force on International Disaster Responses, it was not surprising to find that our 11-member group, which represented 11 different organizations, presented 11 different positions on how acute disaster medical care should be provided. Perhaps Dr. Remi Russbach, Chief Medical Officer for the International Red Cross, underestimated the issue most delicately. He wrote that, "Owing to the large number of organizations willing to participate in relief activities, and owing to logistic, administrative, and political constraints, an ideal situation is hard to reach." We found this to be quite the case at the outset of our deliberations.

After spending a week immersed in formal presentations during the daytime, and informal discussions during lunch and evening social activities, what began as a very abstract, amorphous sketch, began to gain more detail and definition. At the conclusion of the Task Force sessions, each member began to see the merits and pitfalls of the 11 points of view expressed by the members, and a consensus began to evolve. At the final working session, a draft of a position paper was presented for consideration by the members. Essentially, the 
panelists were asked to look at a disaster as a series of ever-expanding concentric circles, much like the ripples seen when a pebble is thrown into a pool of water. The initial point of impact is the disaster event itself, e.g., typhoon, hurricane, flood, earthquake, pipeline explosion, chemical release, or other large-scale incident capable of producing great numbers of injuries which overwhelm day-to-day emergency responses.

As we have seen time and again, from Armenia to San Francisco, the initial circle of responses to a catastrophe will come from those most immediately available to the focus of the event-the uninjured survivors. Without training and preparedness, local citizens will not act in an effective medical manner. The landmark study by the joint SovietAmerican research team following the Armenian earthquake of December 1988, demonstrated that life-supporting first aid virtually was non-existent. The researchers showed that the many health care workers surveyed believed that this type of training, coupled with education in simple rescue techniques, could have reduced significantly the morbidity and mortality which resulted from this tragedy.

The second level of disaster medical response consists of the existing, everyday medical and paramedical personnel. Whatever level of urgent-care, medical personnel respond to the disaster, there should be a plan for their deployment in this type of a setting. Because of the increased magnitude presented by the disaster, the urgent-care medical response cannot be "the same as our usual response...only bigger." The environment is likely to be hazardous, the numbers will outstrip resources both in manpower and equipment, and some of the emergency caregivers themselves, might become casualties of the disaster. Virtually simultaneous with this ripple will be the activation of police and fire personnel. These individuals must be trained in basic rescue and extrication techniques as well, because they likely will be pressed into service to perform just these types of tasks.
Another of the concentric circles of responses will involve a system of transportation of victims, responders, and equipment and supplies into and out of the disaster zone.

In an effort to handle such disasters better, ongoing evaluations of local and regional disaster risks must be undertaken, including the presence of hazardous materials, underground explosive pipelines, regional electrical power plants, and geological hazards such as earthquake faults, volcanoes, and landslide zones. Similarly, meteorological hazards also must be defined, as well as the structural engineering characteristics of buildings and their ability to withstand an insult from the likely hazards within the assessed area.

Once such an incident occurs, the authorities-in-charge must define where casualties will be taken, who will staff them, how those individuals will be trained, and what equipment and supplies will be on-site to be used in the provision of shelter and medical care.

Thought must be given to the advantages and disadvantages of having shelters and medical aid facilities together or separate. The whole community that will need the services of these centers must be educated in the location of and what to expect of such facilities. In the years of my childhood, the 1950s, we were better prepared for disaster than are our children today. Every child was taught a pattern of responses in the event of a nuclear attack. If at school, when the city air raid sirens sounded, we were instructed to leave our classrooms and go into the corridors, face the walls of the hallways, and cover our eyes to save them from damage caused by the brilliance of a nuclear blast. At home, we were encouraged to have food and water supplies in our basements, so as to survive there during the period of highest radioactive fallout. How foolish we all were to think that this would matter, what with the intense heat and radiation of a thermonuclear detonation. But how foolish are we today, to neglect teaching our citizens how to respond to something like a major earthquake, 
which might have the destructive force of a bomb, without the radiation or heat. In the more realistic scenario of a natural or man-made catastrophe, the general public, as well as the police, fire, ambulance technicians, and shelter support personnel must be educated in the location and capabilities of these disaster centers.

To interface the many individuals involved in the expanding layers of a coordinated disaster response, adequate communication capabilities are critical to any mass casualty management system. These must include multiple links to the casualty centers so that the needs of these centers can be met by the incident managers. The incident managers also will need to handle requests for regional assistance.

Because of the overwhelming nature of these events, a disaster preparedness plan must be established at the regional/ state/provincial level, and exercised, critiqued, and revised on a regular basis. Additionally, national health policy needs to include a coordinated, interdisciplinary approach to disaster responses, including defined roles and participation of both the military and voluntary aid agencies.

Globally, an inventory should be established for cataloging and updating the many voluntary aid and mobile disaster units available worldwide. Ideally, such units should be self-sufficient, and equally equipped, staffed, trained, and certificated by a neutral body, so that any nation requesting aid from such a regional team, would know what that team was capable of doing. These teams could be positioned strategically around the globe, so as to permit a response time to a disaster stricken zone within a matter of hours, rather than days.

Finally, international relief agencies, national disaster response teams, and international health organizations should work together to improve the availability, capability, and effectiveness of international disaster efforts. These efforts should be based on the past performance of these responders, as well as on the specific needs of the disasteraffected area. Ideally, a single coordinating agency should be responsible for the deployment of all such assistance.

Essentially these points were discussed, reviewed, and ultimately approved by the Task Force members. The recommendations then received the enthusiastic endorsement of the General Assembly of the Congress. I present them to you here, in this forum of international experts convened in the historic city of Moscow, for further consideration, discussion, and comment. We would like you to contribute further to the betterment of disaster medicine by working to make some of these points a reality. One of the founders and past president of the WAEDM, Dr. Peter Safar, has made it his life's work to provide better immediate life-supporting first aid. We would like to see these skills taught to all citizens, and wish to promote these principles and training tools across the globe. Similarly, our vision for standardizing the many international medical response teams, and making them accountable for both quality and promptness, seems less of a fantasy and more valid as time goes by. We plan to continue the work of the Task Force on International Disaster Responses during the coming year, working closely with members who have access to and participate with the World Health Organization, the International Red Cross and Red Crescent Societies, and United Nations Disaster Relief Organization. This is timely particularly given the United Nations commitment to the $1990 \mathrm{~s}$ as the International Decade of Natural Disaster Reduction.

I am truly honored to have been invited to be present at this important conference. In return, and on behalf of the WAEDM and our President, Dr. Peter Baskett, and the Executive Committee, I extend to you our invitation to join with us in working together to tackle these formidable goals of providing improved education, research, and field practice of Emergency and Disaster Medicine world wide. 

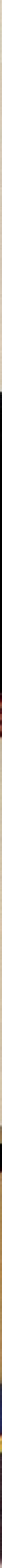

hen the possibility of spinal injury is present and the patient must be immobilized for transport, why take the "light" approach? The Evac-U-Splint Mattress offers fast, full-body immobilization, in the position of injury, without inward point pressure.

When the patient is placed in the EvacU-Splint Mattress it conforms to every body
THE EVAC-U-SPLINT SYSTEM"MN

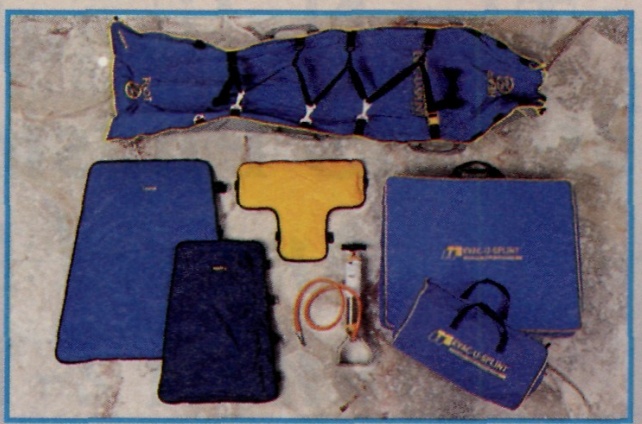

TRY IT NOW, FREE!

Your agency can try the Evac-U-Splint System for 30 days with no obligation. Also, A FREE training video on the System is available. contour comfortably, ensuring spinal immobilization...unlike rigid, hardwood backboards which fail to conform to the patient's body. The mattress is a part of the complete Evac-USplint System which includes color-coded vacuum splints for extremities, a vacuum pump, and carrying cases. Each unit is durable, efficient to use, and surprisingly affordable.
See us at Booth 67 7th World Congress on Emergency \& Disaster Medicine May 13-16, 1991 


\section{Anpouncing}

\section{The Only Place To}

Be.In June

The Meeting for

\section{EMS Medical}

Directors, Nurses, Administrators,

EMT's, Paramedics

\section{and All EMS}

Personnel

The National Association of EMS Physicians Seventh Annual Meeting. June 12-16, 1991

Buena Vista Patace Orlaindo, Florida. 
NAEMSP Annual Meeting Preliminary Program: June 14 - 16, .1991:

Trauma System Development

Integrating the Trauma System and the EMS System

New Directions in EMS Communications

Changing Technology in Communications and it's Implications

Equipment Options

12 Lead Electrocardiography

Role of the Physician in Medical Control of Dispatch

Emergency Department Overcrowding and Ambulance Diversion

Medical Legal Issues E Risk Management

Integrating the Basic EMS \& The First Responder thto the EMS System Volunteerism in EMS

Subspecialty Training in Emergency Medical Services

- Special Scientific Paper and Poster Sessions

Special Tracks to Include: Rural, Air Medical Services,

International, \& The Emergency Medical Dispatch Course

Rural EMS Track

Current status of EMS legislation featuring HR 1602 Rural EMS:

Where have we been, Where are we E Where should we be going?

Innovations in Rural EMS: A necessary impossibility?

Tackling the problems of Rural EMS.

Air Medical Services Track

Air Medical Transport History E Development

Components of Flight Physiology

Advantages/Disadvantages of Variously Configured Flight Safety

Features Including Landing Zones, Emergency Procedures E Equipment
NAEMSP Will Host the National

EMS Medical Director Course

June 12 - 13, 1991

This two day preconference workshop includes recognized experts in various aspects of prehospital care. The National EMS Medical Director's Course has been developed with the Medical Director AND leaders in Emergency Medical Services in Mind. Students will be provided with a comprehensive syllabus that will include sample contracts, run sheets, recommended reading material and other resources to aid the medical directior and lead administrators of EMS Systems.

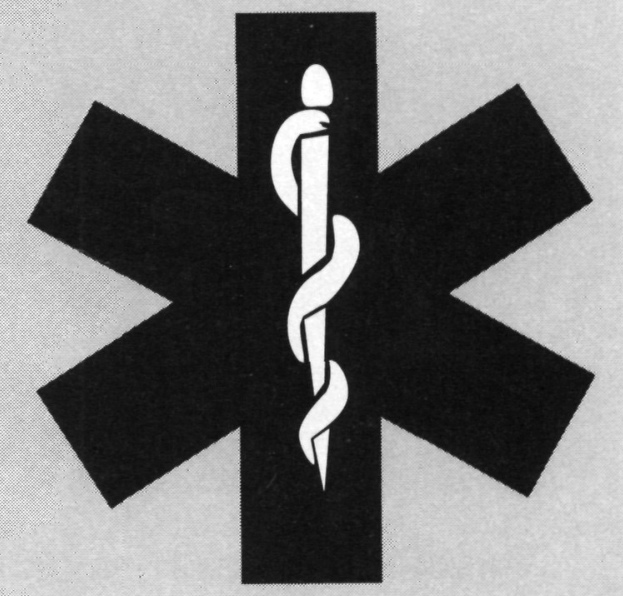

\section{Seventh Annual Meeting Request Form Conference \& Exposition June 12-16, 1991}

Preconference: June 12-16th Committee Meetings: June 13th Buena Vista Palace, Orlando, Florida . The Place To Be In June Is With NAEMSP!

J please Send Me Additional Information

"Name: Title:

Organization:

Address.

City: State: Zip:

Phone:

Mail To: Kathleen M. Stage National Coordinator NAEMSP 230 McKee Place Suite 500 Pittsburgh, PA 15213 (412) 578-3222 


\section{Education in the Heart of Seattle}

The Seventh Biennial International Educational Conference

Emergency Cardiac Care Update 1992 APRIL 9-12, 1992

SEATTLE SHERATON HOTEL \& TOWERS - SEATTLE, WASHINGTON

Presented by

Citizen CPR Foundation, Inc. in conjunction with The Conference Corporation

Plan Now to Attend and Present at the Premier International Conference on Emergency Cardiac Care ECCU ' 92 will focus on the prevention of cardiovascular disease through use of the four links in the chain of survival: early access, early CPR, early defibrillation and early advanced life support. The conference will provide a dynamic forum for individuals interested in developing, improving and expanding public and professional education in emergency cardiac care.

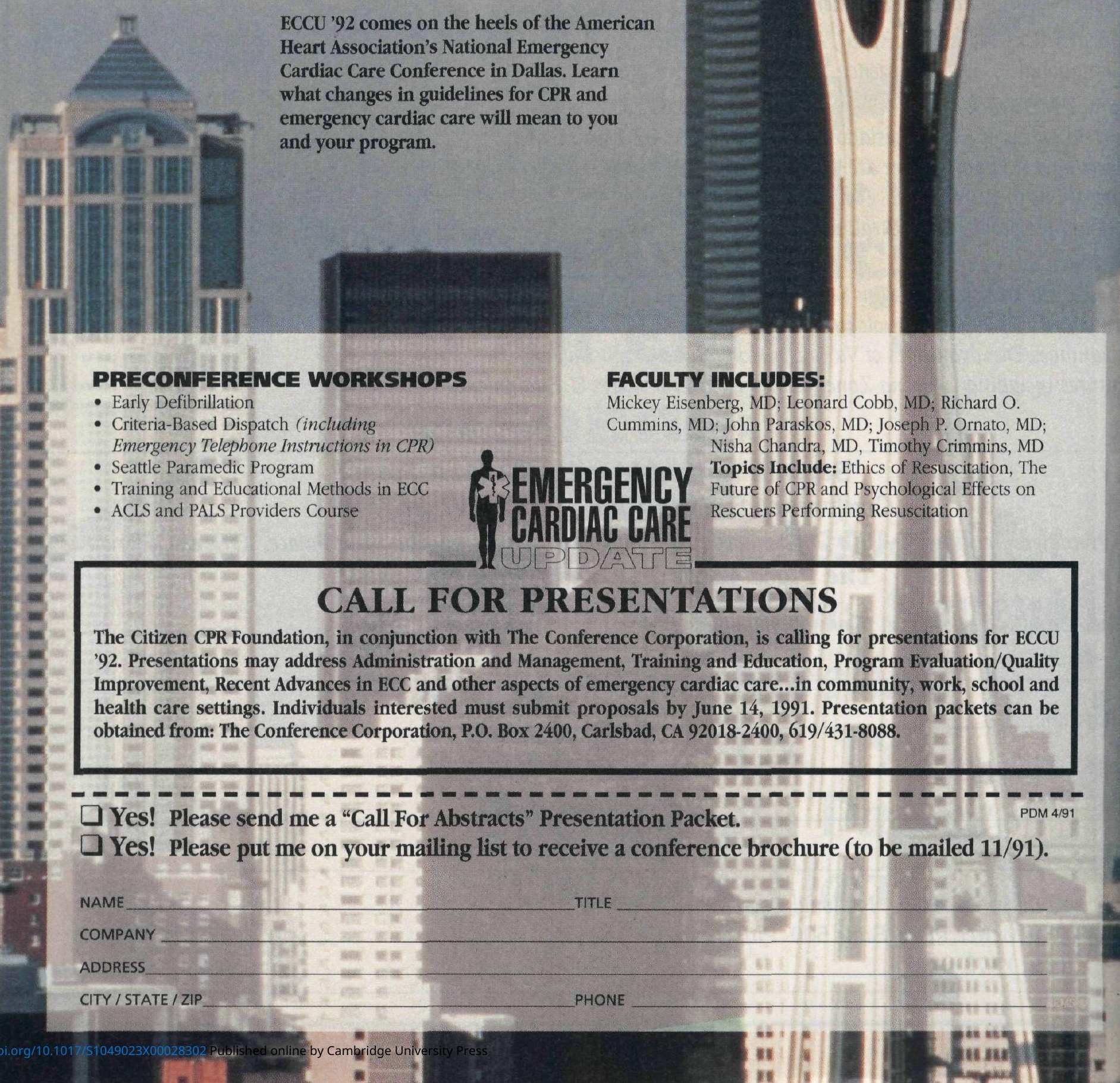


